\title{
CARACTERISTICAS DA MORTE SÚBITA TIDA COMO NÃO ESPERADA NA DOENÇA DE CHAGAS
}

\author{
Aluizio Prata1, Edison Reis Lopes² e Edmundo Chapadeiro'
}

\begin{abstract}
Trinta e cinco individuos falecidos subitamente e de modo inesperado foram necropsiados em Serviços Médico-Legais em Uberaba e Uberlândia. A sorologia do liquido pericárdico e os achados anatomopatológicos estabeleceram o diagnóstico de doença de Chagas. Todos, exceto dois, eram do sexo masculino e tinham idade média de 38 anos. Resolvemos fazer uma investigação retrospectiva procurando obter de familiares e amigos e nos registros médicos informaçôes sobre as circunstâncias do óbito e manifestações que pudessem constituir possiveis indicios de doença cardiaca e de comprometimento de outros órgãos. Em 31,2\% não havia quaisquer sintomas ou suspeita de cardiopatia. Contudo, em $57,1 \%$ dos casos conseguimos detectar história de tonturas $(42,8 \%)$, dispnéia de esforço (48\%), perda de consciência $(34,2 \%)$ e palpitaçōes $(31,4 \%)$. A disfagia e ou a obstipação estavam presentes em $38 \%$. Não houle correlaçào entre a sintomatologia e a intensidade da miocardite. Em $56 \%$ o èxito letal surgiu enquanto desen volviam esforco fisico ou tinham emocào. Pelo modo como ocorreu o obito pode-se concluir que a iminència deste nào foi pressentida pelo paciente ou circunstantes em 43,8\% dos casos; no restante, o óbito súbito foi precedido de indicios, tais como gestos, pedidos de ajuda, etc. Somente em 5 dos 35 casos o eletrocardiograma havia sido realizado meses ou anos antes do obito: todos apresentavam alteracóes.
\end{abstract}

Palavras chaves: Doença de Chagas. Morte sủbita. Cardiopatia chagásica.

Em 1912 Carlos Chagas $^{2}$ dizia ser impressionante o numero de pessoas falecidas repentinamente por doença de Chagas. Acrescentava que eram poucas a familias que não tinham perdido alguns de seus membros, falecidos ainda jovens e em plena atividade com aparència de boa saúde ${ }^{3}$. Chagas e Villela ${ }^{4}$ afirmavam não saber de outra patologia que ocasionasse a morte súbita em percentagem tão elevada quanto o faz a tripanossomiase americana. A doença de Chagas é a causa mais freqüente de morte súbita em algumas regiōes onde a doença é endêmica ${ }^{8}$. Luigi Bogliolo disse a um de nós (ERL), com muita propriedade, que a morte súbita era um acidente na evolução da doença de Chagas. Ela pode suceder na fase aguda e na crônica. Se surge em pacientes com evidente insuficiência cardiaca é tida como esperada, por isso os legistas preferem excluir esta variedade da definição de morte súbita; cerca de $38 \%$ dos cardiopatas chagásicos crônicos descompensados têm este tipo de morte ${ }^{15}$. Se o paciente nào tem doença clínica aparente, a morte súbita é inesperada, por isso des-

Trabalho realizado com o auxilio do Conselho Nacional de Desenvolvimento Cientifico e Tecnologico.

1. Universidade de Brasilia e 2. Faculdade de Medicina do Triàngulo Mineiro.

Recebido para publicaçào em 9/5/85. perta atenção, assusta e constrange: ela ocorreu em $37.5 \%$ dos óbitos por doença de Chagas na área endêmica de Sào Felipe ${ }^{11}$.

Relativamente, são poucos os trabalhos que se dedicam ao tema. Porto ${ }^{4}$, Chapadeiro e cols 6 , Pedace $^{13}$ e Lopes ${ }^{8}$ discutiram a matéria, especialmente sob o ponto de vista médico-legal. A possibilidade de diagnóstico sorológico pós-mortem da doença de Chagas $^{15}$ e a utilização do Serviço Médico Legal em Uberaba e Uberlândia permitiu a Lopes ${ }^{8}$ e Lopes e cols $^{9}$ a realização de necrópsias em pacientes chagásicos falecidos subitamente e a descrição dos aspectos anatomopatológicos. Achamos que haveria interesse em se conhecer melhor outras caracteristicas clínicas e epidemiológicas destes casos.

\section{MATERIAL E MÉTODOS}

Em 35 indivíduos necropsiados no Serviço de Medicina Legal de Uberaba e de Uberlândia, falecidos subitamente, estabelecemos o diagnóstico sorológico e anatomopatológico de doença de Chagas. $O$ diagnóstico sorologico foi feito pela colheita de liquido pericárdico durante a necrópsia, segundo metodologia já descrita ${ }^{10}$. Em 14 casos o exame histopatológico do 
coração foi mais extenso e a intensidade da miocardite quantificada em graus $(+,++$ ou +++$)$. Através de visitas domiciliares conseguimos informações sobre todos os óbitos. As informações em $58 \%$ dos casos foram obtidas menos de 1 ano após o óbito e no restante entre 2 a 10 anos. Os informantes eram pessoas da familia e em três ocasiões amigos ou vizinhos. Procuramos saber como decorreu o óbito, se havia registro de atendimentos médicos, sintomatologia relacionada à doença de Chagas, ocorrência em familiares e afastamento da área endêmica.

\section{RESULTADOS}

Dos 35 pacientes falecidos subitamente 33 eram do sexo masculino. A idade era em média 38 anos, sendo 13 anos em 1 (2,8\%), entre $20-29 \mathrm{em} 8$ (22,8\%), 30-39 em 9 (25,7\%), 40-49 em 12 (34,2\%) e $50-59$ em 5 (14.2\%). Todos provinham de áreas endêmicas, de onde haviam se afastado, em média, há 11 anos (variando de poucos dias a 23 anos).

Quanto às profissões havia três pedreiros, três lavradores, três operários, dois fiscais e um de cada das seguintes: pintor, servente, vaqueiro, jardineiro, motorista, borracheiro, barbeiro e lavadeira. Três eram aposentados e dos demais não colhemos informações, quanto à profissão.

Havia antecedentes familiares de morte súbita em 18 deles e ausência em 4 e não havia informação precisa no restante.

Dos 35 individuos investigados, em 20(57,1\%) conseguimos reconhecer a seguinte sintomatologia, provavelmente relacionada à cardiopatia chagásica: tonturas, $15(42,8 \%)$; dispnéia de esforço, $14(40 \%)$; perda de consciência, $12(34,2 \%)$; palpitações, 11 $(31,4 \%)$; dor precordial, $4(12,5 \%)$; episódios de taquicardia, $2(6,2 \%)$; edemas, $1(3,1 \%)$; bradicardia, $1(3,1 \%)$. Quanto à perda de consciência, ela estava associada a tonturas em 9 pacientes. Em 8 houve somente um episódio de perda de consciência, em 2 houve dois e somente em 1 paciente houve vários episódios antes do óbito.

Eles apresentavam ainda outros sintomas, tais como cefaléia $(31,2 \%)$, nervosismo $(18,7 \%)$, mialgias $(9,4 \%)$, emagrecimento $(6,2 \%) \mathrm{e}$, em menor freqüência, angústia, náuseas, mal-estar, insônia, dor abdominal e cãibra.

Quinze não tinham sintomatologia cardiaca apesar de constar que 1 era aposentado por cardiopatia (supeita-se que baseado somente em testes sorológicos); 1 tinha edemas maleolares e 2 evitavam esforços físicos (presumidamente pessoas com pouca disposição para o trabalho). Em $11(31,4 \%)$ não havia nenhuma sintomatologia e nem suspeita de cardiopatia.
Apuramos ainda haver sintomatologia de “engasgo" e/ou obstipação em 8 , ausência dela em 13 e sem informação nos demais. Dos 8 com distúrbios digestivos, 5 estavam entre os $19 \mathrm{com}$ sintomatologia cardiaca, 1 entre os suspeitos e 2 entre os sem sintomatologia e sem suspeita de cardiopatia. Assim, em $9(22,9 \%)$ pacientes não havia queixa alguma que pudesse ser relacionada à doença de Chagas.

De 26 em que conseguimos informações sobre atendimento médico, $17(65,4 \%)$ tinham procurado o facultativo e em 10 destes foi feito o diagnóstico de cardiopatia.

Houve testemunha do óbito em $32(91,4 \%)$ dos 35 casos. No momento do óbito os individuos desenvolviam a seguinte atividade: esforço fisico intenso, $3(8,6 \%)$; esforço físico leve, $9(25,7 \%)$; emoção, $5(14,3 \%)$; esforço físico e emoção, $1(2,9 \%)$; atividades normais, $14(40 \%)$; repouso, $3(8,6 \%)$.

Nos 32 testemunhados, o obito foi instantàneo, com a subitaneidade de um raio, e aparentemente não foi pressentido pelo paciente ou circunstantes em $14(43,8 \%)$ ocasiões, pois não houve tempo de apear da bicicleta, de esboçar um gesto durante o jogo de cartas, de interromper a caçoada ou de evitar a queda brusca durante a marcha e nem se ouviu um gemido ou suspiro; 11 dos 14 pacientes faleceram quando estavam repousando ou executando atividades normais. $O$ óbito foi precedido de sintomas premonitórios em 18 $(56,2 \%)$ os quais foram de curta duração em 14 , tendo o paciente emitido gemido, gesto de dor ou de desespero, pedido de ajuda, apoiado em algum objeto ou sentou-se; sendo que somente em quatro a vida se prolongou por minutos, após queixa de mal-estar, tonturas, náuseas ou palidez. Não houve correlação entre a sintomatologia apresentada por alguns doentes e a morte instantânea.

Cinco pacientes tinham eletrocardiogramas. Um deles, 7 anos antes do óbito, acusa taquicardia sinusal, sobrecarga atrial direita e alterações difusas da repolarização ventricular; e, um ano antes do óbito, extrassistoles ventriculares, distúrbios da condução intra-atrial e alteração primária da repolarização ventricular. Outro paciente tinha eletrocardiograma dois anos antes do óbito acusando batimentos ventriculares prematuros mono e polifocais, com bigeminismo e marcapasso mutável, bloqueio de ramo esquerdo, alterações primárias e secundárias da repolarização ventricular, sinais indiretos de sobrecarga atrial direita e sinais presuntivos de sobrecarga ventricular esquerda. $O$ terceiro, três meses antes do óbito, exibe extrassístoles ventriculares e supraventriculares, bigeminismo, e alteraçōes primärias de repolarização ventricular. $O$ quarto paciente tinha eletrocardiograma quatro meses antes do óbito, apresentando desvio do eixo elétrico para a esquerda, alterações difusas da repolarização ventricular e onda 
Prata A, Lopes ER, Chapadeiro E. Características da morte súbita tida como não esperada na doença de Chagas. Revista da Sociedade Brasileira de Medicina Tropical 19: 9-12, Jan-Mar, 1986

Q patológica. Quanto ao último paciente havia referência de eletrocardiograma anormal dois anos antes do obito.

Os achados anatomopatológicos se sobrepõem aos já descritos nos chagásicos falecidos subitamente ${ }^{9}$. A intensidade da miocardite em comparação com a sintomatologia foi a seguinte:

\section{Óbito Miocardite}

\section{Sintomatologia}

\section{(n.)}

\begin{tabular}{|c|c|}
\hline$+/++$ & Dispnéia e palpitações. \\
\hline+++ & Tonturas 15 dias antes do óbito. \\
\hline & Episódios de perda da consciência \\
\hline$++1+++$ & Assintomático. \\
\hline+++ & $\begin{array}{l}\text { Dispnéia, edemas e perda de cons- } \\
\text { ciência. }\end{array}$ \\
\hline+ & Dispnéia, palpitações e tonturas. \\
\hline+++ & Assintomático. \\
\hline$++1+++$ & - Assintomático. \\
\hline++ & $\begin{array}{l}\text { Dispnéia, palpitações e perda da } \\
\text { consciência. }\end{array}$ \\
\hline+++ & Assintomático. \\
\hline$+/++$ & Assintomático. \\
\hline++ & $\begin{array}{l}\text { Assintomático. Aposentado por } \\
\text { cardiopatia. }\end{array}$ \\
\hline & - Assintomático. \\
\hline & Assintomático. \\
\hline
\end{tabular}

Aparentemente não houve correlação entre a intensidade da miocardite chagásica e a sintomatologia.

\section{DISCUSSÃO}

Nossos dados estão sujeitos a criticas, por terem sido obtidos através de informações indiretas e principalmente por se referirem a fatos ocorridos por vezes há anos. Contudo, uma investigação como a realizada, com familiares e amigos, pode trazer fatos não revelados imediatamente após o óbito. Assim, mostramos que na maioria dos chagásicos com morte súbita tida como inesperada, uma investigação retrospectiva conseguiu evidenciar dispnéia de esforço, palpitações, tonturas e episódios de perda de consciência. Todos continuaram desempenhando suas atividades e aos circunstantes o óbito era imprevisivel. Onze $(31,4 \%)$ dos nossos pacientes não referiam queixas e nem havia supeita de ter cardiopatia. A rigor, somente estes onze chagásicos teriam tido morte súbita inesperada. Porem, em todos os 35 chagásicos da atual casuistica, o obito foi imprevisivel tanto para familiares e circunstantes como para o médico legista. Foi por esta razão que os cadáveres foram encaminhados aos Serviços Médicos Legais. Eles não tinham diagnóstico de doença clinica aparente até que colhemos os dados apresentados neste trabalho. Em muitos deles persiste a dúvida se sintomas isolados como tonturas seriam indicativos de uma cardiopatia. Nossos dados não deixam dúvida de que a morte súbita pode acometer chagásicos assintomáticos.

É importante sabermos se ela pode ocorrer em pessoas com eletrocardiograma normal e portanto na chamada forma indeterminada. São poucas as referências de eletrocardiogramas em morte súbita inesperada. Cinco pacientes desta nossa casuistica, nove de Prata e Macêdo em São Felipe (dados não publicados) e sete de Dias ${ }^{7}$ em Bambui, tinham eletrocardiogramas realizados alguns anos antes do óbito $\mathrm{e}$ estes eram anormais. Porto ${ }^{14}$ refere que $5(7,2 \%) \mathrm{em}$ 69 de seus chagásicos falecidos de morte súbita tinham eletrocardiograma normal pouco tempo antes do óbito e Manzullo e cols ${ }^{12}$ mencionam o mesmo em $1(6,6 \%)$ de seus 15 chagásicos falecidos repentinamente. Os casos de Porto e Manzullo, embora sem comprovação necroscópica, sugerem que a morte súbita ocorre em pacientes com diagnóstico de forma indeterminada. De qualquer modo seria uma raridade e não mudaria o bom prognóstico dessa forma clínica.

A morte súbita é pouco freqüente durante o periodo de repouso. Não se pode afastar a relação entre a morte súbita e esforço fisico ou emoção, pois seria difícil explicar por que a metade dos nossos obitos ocorreu aparentemente em conseqüência dos ocasionais periodos de sobrecarga física ou emocional.

Uma das caracteristicas da morte súbita nos chagásicos è a instantaneidade, sendo esta mais freqüente quando ocorre em individuos executando atividades normais ou em repouso. Os óbitos durante esforço físico têm tendência a ser menos instantâneos.

Como nosso material não foi selecionado estamos convencidos de que a morte súbita inesperada é muito mais freqüente no sexo masculino, sem que saibamos a explicação.

$\mathrm{O}$ estudo das caracteristicas da morte súbita nos chagásicos facilita o conhecimento dos fatores de risco, e pode auxiliar na identificação dos pacientes que necessitam cuidados preventivos.

\section{SUMMARY}

Thirty five individuals who died suddenly and unexpectedly were autopsied at Medico-Legal Services in Uberaba and Uberlandia (State of Minas Gerais-Brazil). Serology of the pericardial fluid and histopathological findings established a diagnosis of Chagas' disease. All, with two exceptions were males and their mean age was 38 years. We decided to conduct a retrospective investigation regarding the manner of death of chagasic patients who died suddenly from information obtained from family members and friends. The questionaire explored 
Prata A, Lopes ER, Chapadeiro E. Características da morte súbita tida como não esperada na doença de Chagas. Revista da Sociedade Brasileira de Medicina Tropical 19: 9-12, Jan-Mar, 1986

possible cardiac and systemic factors related to the risk of such an event. In $31.2 \%$ there were no symptoms nor suspicion of cardiopathy. However, in $57,1 \%$ it was possible to detect a history of dizziness $(42,8 \%)$, dvspnoea on exertion ( $48 \%)$, loss of conciousness $(34,2 \%)$ and palpitations $(31,4 \%)$. Dysphagia and or constipation was present in $38 \%$. There was no correlation between symptomatology and the intensity of myocarditis on histopathological examination. In 56\% the death occurred during physical exercise or an emotional episode. From the manner of death we can conclude that there was no indication that such an event would occur in $43.8 \%$ of patients. In the rest the death was preceeded by signs on the part of the patient that he was in difficulty. Electrocardiograms were available from only five patients: all were abnormal.

Key words: Chagas' disease. Sudden death. Chagasic cardiomyopathy.

\section{REFERÊNCIAS BIBLIOGRÁFICAS}

1. Almeida HO. Chapadeiro E. Reação de Guerreiro e Machado no lıquido pericardico de chagasicos crónicos. com e sem ICC. 90 Congresso Brasileiro de Patologia. Rio de Janciro. 1972.

2. Chagas C. O mal de Chagas. Archivos da Sociedade de Medicina e Cirurgia de São Paulo 3: 34-66, 1912.

3. Chagas C. Aspectos clinicos y anátomo-patológicos de la tripanosomiasis americana. La Prensa Medica Argentina 3: 125-127, 137-138, 153-158, 1916.

4. Chagas C, Villela E. Forma cardiaca da trypanosomiase americana. Memórias do Instituto Oswaldo Cruz 14:5-61, 1922.

5. Chapadeiro E, Furtado JHM, Lopes ER, Hial W, Percira FEL. Netto AC. Miziara LJ. The complement fixation test of Guerreiro and Machado in the pericardial fluid in chronic Chagas's heart disease. The Journal of Tropical Medicine and Hygiene 71:81-82, 1968.

6. Chapadeiro E. Lopes ER. Raso P, Brauna AD. Importáncia do reconhecimento da Doença de Chagas em Medicina Legal. O Hospital 76:249-257. 1969.

7. Dias JCP. Doença de Chagas em Bambui, Minas Gerais, Brasil. Estudo clínico-epidemiológico a partir da fase aguda, entre 1940 e 1982 . Tese de Doutoramento, Belo Horizonte, 1982.

8. Lopes ER. Morte súbita em área endêmica da doença de Chagas. Sua importancia médico-legal. Tese para Professor Titular. Faculdade de Medicina do Triângulo Mineiro, Uberaba, Minas Gerais, 1981.

9. Lopes ER. Chapadeiro E. Almeida HO, Rocha A. Contribuição ao estudo da anatomia patológica dos corações de chagásicos falecidos subitamente. Revista da Sociedade Brasileira de Medicina Tropical 9:269282, 1975.

10. Lopes ER, Chapadeiro E, Batista SM, Cunha JG, Rocha A. Miziara L. Ribciro JU, Porto RJ. Post-mortem diagnosis of chronic Chagas' disease: comparative evaluation of three scrological tests on pericardial fluid. Transactions of the Royal Society of Tropical Medicine and Hygiene 72:244-246. 1978.

11. Macêdo VO. Influência da exposição à reinfecção na evoluçào da doença de Chagas. Tese para Livre Docência. Faculdade de Medicina da Universidade Federal do Rio de Janeiro. Rio de Janeiro, 1973.

12. Manzullo E, Dorraidon MA. Anales de la VI Reunion Nacional de Investigadores de la Enfermedad de Chagas, Buenos Aires, P. 14, 1983.

13. Pedace EA. Enfermedad de Chagas - Mazza y muerte subita. Aportaciones histopatologicas - forenses. La Prensa Medica Argentina 65:565-572, 1969.

14. Porto CC. Contribuição do eletrocardiograma no prognóstico e evolução da doença de Chagas. Tese. Faculdade de Medicina da Universidade Federal de Minas Gerais. Belo Horizonte, 1963.

15. Prata A. Prognóstico e complicações da doença de Chagas. Revista Goiana de Medicina 5:87-96, 1959. 